\title{
Effects of coconut and fish oils on ruminal methanogenesis, fermentation, and abundance and diversity of microbial populations in vitro
}

\author{
A. K. Patra*† and Z. Yu*1 \\ *Department of Animal Sciences, The Ohio State University, Columbus 42310 \\ †Department of Animal Nutrition, West Bengal University of Animal and Fishery Sciences, 37 K. B. Sarani, Belgachia, Kolkata 700037, India
}

\begin{abstract}
Coconut (CO) and fish (FO) oils were previously shown to inhibit rumen methanogenesis and biohydrogenation, which mitigates methane emission and helps improve beneficial fatty acids in meat and milk. This study aimed at investigating the comparative effects of $\mathrm{CO}$ and FO on the methanogenesis, fermentation, and microbial abundances and diversity in vitro rumen cultures containing different doses $(0,3.1$, and $6.2 \mathrm{~mL} / \mathrm{L})$ of each oil and $400 \mathrm{mg}$ feed substrate using rumen fluid from lactating dairy cows as inocula. Increasing doses of $\mathrm{CO}$ and FO quadratically decreased concentrations of methane, but hydrogen concentrations were only increased quadratically by CO. Both oils linearly decreased dry matter and neutral detergent fiber digestibility of feeds but did not affect the concentration of total volatile fatty acids. However, $\mathrm{CO}$ reduced acetate percentage and acetate to propionate ratio and increased the percentages of propionate and butyrate to a greater extent than FO. Ammonia concentration was greater for $\mathrm{CO}$ than FO. As determined by quantitative real-time $\mathrm{PCR}, \mathrm{FO}$ had greater inhibition to methanogens than $\mathrm{CO}$, but the opposite was true for protozoal, Ruminococcus flavefaciens, and Fibrobacter succinogenes. Ruminococcus albus was not affected by either oil. Denaturing gradient gel electrophoresis (DGGE) profiles revealed that bacterial and archaeal community composition were changed differently by oil type. Based on Pareto-Lorenz evenness curve analysis of the DGGE profiles, CO noticeably changed the functional organization of archaea compared with FO. In conclusion, although both $\mathrm{CO}$ and FO decreased methane concentrations to a similar extent, the mode of reduction and the effect on abundances and diversity of archaeal and bacterial populations differed between the oils. Thus, the use of combination of $\mathrm{CO}$ and FO at a low dose may additively lower methanogenesis in
\end{abstract}

Received September 14, 2012.

Accepted November 23, 2012.

${ }^{1}$ Corresponding author: yu.226@osu.edu the rumen while having little adverse effect on rumen fermentation.

Key words: coconut and fish oils, methanogenesis, microbial diversity, rumen fermentation

\section{INTRODUCTION}

Hydrogenotrophic methanogenesis in the rumen accounts for a loss of 2 to $12 \%$ of the ingested gross energy (Johnson and Johnson, 1995). This not only lowers the efficiency of feed energy utilization, but also contributes to emission of methane as a potent greenhouse gas from ruminants. Therefore, researchers are exploring various technologies and policies to mitigate enteric methane emissions (Beauchemin et al., 2008; Martin et al., 2010; Patra and Saxena, 2010). However, most of the dietary interventions aimed to reduce methane production in the rumen adversely affect fermentation and productivity (Patra, 2012). Few dietary interventions appeared to be promising to reduce methane emissions while maintaining or improving the productivity of ruminants (Martin et al., 2010; Patra, 2012). Supplementation of fats is one of the dietary options recognized to decrease enteric methane emissions (McAllister et al., 1996; Beauchemin et al., 2008). Besides increasing the energy density of diets and improving the energy status of high-yielding lactating dairy cattle (Coppock and Wilks, 1991), fat supplementation can also increase concentrations of n-3 PUFA and n-3 conjugated linoleic acids (CLA) in milk and meat, depending on the fat source, which have beneficial effects on human health (Lock and Bauman, 2004).

The reported efficacy of oils on rumen methanogenesis varies dramatically among studies, depending upon on the concentration, type, and fatty acid composition of the fats used, as well as the nutrient composition of the diets (Machmuller, 2006; Beauchemin et al., 2008). For example, several studies reported substantial reductions in rumen methane production by supplementation of oils, especially oils rich in medium-chain $\left(\leq \mathrm{C}_{14}\right)$ fatty acids (MCFA) or long-chain $\left(>\mathrm{C}_{14}\right)$ unsaturated fatty acids (UFA) (Fievez et al., 2003; Jordan et al., 2006; Machmuller, 2006). However, contradictory re- 
ports claim that oil infusion to the rumen of up to $5 \%$ did not affect methane production (Cosgrove et al., 2008). Coconut oil (CO) contains high concentrations of medium-chain (about 80\%) saturated (about 90\%) FA, whereas fish oil $(\mathbf{F O})$ is rich in unsaturated (about $75 \%$ ) long-chain (more than 90\%) FA-particularly very long chain ( $\geq$ C20) C20:5n-3 (eicosapentaenoic acid) and C22:6n-3 (docosahexaenoic acid). These 2 types of oils have been exploited in ruminant nutrition to inhibit methanogenesis and to enrich healthpromoting FA (e.g., cis-9,trans-11 CLA and long-chain n-3 FA) in meat and milk (Fievez et al., 2003; Lourenço et al., 2010). We hypothesized that the effects of CO and FO on archaeal and bacterial community composition may differ as fatty acid composition between these 2 types of oils largely differs. Consequently, their influences on inhibition of methanogenesis and fermentation profile could vary in the rumen. A greater understanding of the effects of these oils on rumen microbiome potentially helps develop effective feeding strategies to decrease ruminal methane emissions and to improve ruminant product quality. However, information on the comparative efficacy of oils rich in MCFA (e.g., CO) and long-chain UFA (e.g., FO) on rumen microbiome are not available in the literature. Therefore, this study was undertaken to investigate the effect of $\mathrm{CO}$ and $\mathrm{FO}$ on methanogenesis, fermentation, diversity and abundances of bacteria and archaea in an in vitro rumen model with rumen fluid obtained from lactating dairy cows.

\section{MATERIALS AND METHODS}

\section{Experimental Procedures}

Three concentrations $(0,3.1$, and $6.2 \mathrm{~mL} / \mathrm{L}$ medium $)$ each of $\mathrm{CO}$ and $\mathrm{FO}$ were used in a $3 \times 2$ factorial design for this in vitro study. Fresh rumen fluid was collected as the inoculum at approximately $10 \mathrm{~h}$ after the morning feeding from 2 cannulated lactating Jersey cows that were fed a TMR composed (\% of DM) of corn silage (39\%), a mixture of alfalfa and grass hay (35\%), and a concentrate mixture (26\%). The cows were fed the TMR $(19.0 \mathrm{~kg})$ twice a day at 0600 and $1800 \mathrm{~h}$. During sample collection, the animals were handled following the protocols approved by The Ohio State University Animal Care and Use Committee. The in vitro fermentation was carried out in $120-\mathrm{mL}$ serum bottles in triplicate as described earlier (Patra and $\mathrm{Yu}, 2012$ ). Briefly, the rumen fluid collected from the 2 cows was mixed equally, filtered through 3 layers of cheesecloth in an anaerobic chamber, and used as the inoculum. The medium for the in vitro fermentation was prepared anaerobically according to the procedure of Menke and Steingass (1988). The anaerobic medium $(30 \mathrm{~mL})$ and the inoculum $(10 \mathrm{~mL})$ were dispensed into each $120-\mathrm{mL}$ serum bottle containing $400 \mathrm{mg}$ of ground feed substrate, which was a mixture (1:1 ratio as fed basis) of alfalfa hay (38.8\% NDF) and a dairy concentrate composed mainly of ground corn $(33.2 \%)$, soybean meal (14.2\%), AminoPlus (15.5\%; Ag Processing Inc., Omaha, NE), distillers grains (19.8\%), and wheat middlings $(11.3 \%)$. These serum bottles, with carbon dioxide in the headspace, were sealed with butyl rubber stoppers and incubated at $39^{\circ} \mathrm{C}$ for $24 \mathrm{~h}$ in a water bath with intermittent shaking.

\section{Sampling and Measurements}

After $24 \mathrm{~h}$ of incubation, $\mathrm{pH}$, gas production, methane production, $\mathrm{CO}_{2}$ production, VFA profile, ammonia concentration, apparent digestibility of DM, and NDF were determined as described previously (Patra and $\mathrm{Yu}, 2012$ ). The hydrogen concentrations in the gas samples were estimated by the difference between total gas and combination of methane and carbon dioxide.

\section{Microbial Analysis}

Metagenomic DNA was extracted from $0.5 \mathrm{~mL}$ of each homogenized sample using the repeated bead beating and column purification method as described earlier ( $\mathrm{Yu}$ and Morrison, 2004a). The abundance of total bacteria, total methanogens, total protozoa, Fibrobacter succinogenes, Ruminococcus albus, and Ruminococcus flavefaciens were quantified using respective specific quantitative real-time (q)PCR as reported previously (Sylvester et al., 2004; Stiverson et al., 2011). To minimize potential bias, sample-derived qPCR standards - instead of a single strain - were prepared using the respective, specific PCR primer set and a composite metagenomic DNA sample that was prepared by pooling equal amounts of all the metagenomic DNA samples (Yu et al., 2005). To eliminate the effect from potential primer dimers in the SYBR-based qPCR assays, the fluorescence signal acquired at $86^{\circ} \mathrm{C}$, at which primer dimers were completely denatured, was used in quantifying populations of the microbial groups or species (Yu et al., 2005). The qPCR assay for each species or group was performed in triplicate for both the standards and the metagenomic DNA samples using the same master mix and the same qPCR plate. The absolute abundances of microbial populations were expressed as rrs (16S rDNA) gene copies per milliliter of culture samples.

The bacterial and the archaeal communities in each of the cultures was examined using denaturing gradient 
gel electrophoresis (DGGE; Yu and Morrison, 2004b; $\mathrm{Yu}$ et al., 2008). Briefly, the V3 hypervariable region of the $16 \mathrm{~S}$ rRNA gene of bacteria and archaea was amplified using bacteria- and archaea-specific primers. The confirmed PCR products were resolved using polyacrylamide gels $(8 \%)$ with a denaturant gradient between 40 and $60 \%$. Following staining with SYBR Green I (Molecular Probes, Eugene, OR), the images were captured using a FluorChem Imaging System (Alpha Innotech Corp., San Leandro, CA) and analyzed with the BioNumerics software (Applied Maths Inc., Austin, TX) based on the peak intensities and migration of the bands (Patra and Yu, 2012).

Diversity indices were calculated for each of the cultures as described previously (Patra and $\mathrm{Yu}, 2012)$ : (1) the Shannon-Wiener index, $H^{\prime}=-\Sigma(\mathrm{ni} / \mathrm{N}) \ln (\mathrm{ni} / \mathrm{N})$, (2) the Simpson dominance index, $\lambda=\Sigma(\mathrm{ni} / \mathrm{N})^{2}$, and (3) the evenness index, $\mathrm{e}=H^{\prime} / \operatorname{lnS}$, where $\mathrm{S}=$ total number of bands, ni $=$ peak height of ith band, and $\mathrm{N}=$ sum of the peak heights of all bands of each sample. The species distribution of the bacterial and the archaeal communities was graphically represented by Pareto-Lorenz (PL) evenness curves based on the DGGE profiles, which were constructed as described previously (Mertens et al., 2005; Patra et al., 2012). Briefly, the respective bands for each sample were ranked from high to low based on their band intensities, then the cumulative proportion of bands and their respective cumulative proportion of band intensities were plotted on $x$ - and $y$-axes, respectively (Mertens et al., 2005; Patra et al., 2012).

\section{Statistical Analysis}

Three doses of oil $(0,3.1$, and $6.2 \mathrm{~mL} / \mathrm{L}), 2$ oils $(\mathrm{CO}$ and FO), and interaction of dose $\times$ oil type as fixed effects, as well as incubated serum bottle as random effect were included in the model. The PROC MIXED procedure of SAS Institute (2001) was used for all statistical analyses. Significance was declared at $P<0.05$, whereas $0.05<P<0.10$ values were considered to be a trend. Polynomial contrasts were used to test for linear and quadratic dose effects of each oil. After logarithmic transformation, principal component analyses (PCA) of the DGGE profiles of bacteria and archaea were performed using SAS Institute (2001) to account for normal distribution of the data. Graphically, the PCA visualized the relative similarity of community composition as indicated by the distance among treatments. The PCA scores on the first 3 principal components were further analyzed by multivariate ANOVA (MANOVA) to test for differences in community composition among the treatments using SAS Institute (2001).

\section{RESULTS}

\section{Gas Production and Feed Degradability}

No difference was noted between $\mathrm{CO}$ and $\mathrm{FO}$ in production of total gas - methane, hydrogen, and carbon dioxide - or degradability of the substrate (Table 1). Concentrations of methane, hydrogen, and carbon dioxide in the culture headspace were also unaffected by oil types. No significant oil type $\times$ dose interaction was detected with respect to the above measurements. Compared with the control, however, increasing doses of CO linearly $(P<0.05)$ increased production of total gas, hydrogen, and carbon dioxide, but linearly $(P$ $<0.05)$ decreased degradability of DM and NDF and tended $(P<0.10)$ to decrease methane production. Total gas or hydrogen production was not influenced by FO, but increasing doses of FO linearly $(P<0.05)$ increased carbon dioxide while linearly $(P<0.05)$ decreasing degradability of the substrate and tended to decrease methane production. The concentrations of the gases in headspace were affected by increasing doses of both $\mathrm{CO}$ and $\mathrm{FO}$, with a quadratic decrease in methane by both $\mathrm{CO}$ and FO, a linear and a quadratic increase in carbon dioxide by $\mathrm{FO}$ and $\mathrm{CO}$, respectively, and a quadratic increase in hydrogen by $\mathrm{CO}$. However, FO did not affect hydrogen concentration (Figure 1). Both oils affected the $\mathrm{pH}$ in the cultures quadratically $(P<0.05)$.

\section{Volatile Fatty Acids}

No difference was noted between $\mathrm{CO}$ and FO in their effect on the concentrations of total VFA (Table 2). However, $\mathrm{CO}$ and FO differed $(P<0.01$ to 0.08$)$ in their effect on the proportion of individual fatty acids, except for isovalerate. The addition of $\mathrm{CO}$ resulted in lower proportions of acetate and valerate, as well as a lower acetate to propionate ratio $(\mathbf{A}: \mathbf{P})$, than the addition of FO, but higher proportions of propionate, butyrate, and isobutyrate. Significant oil type $\times$ dose interactions were noted for the effect on VFA profiles. Increasing doses of $\mathrm{CO}$ tended to decrease proportion of acetate linearly, but increased that of butyrate quadratically. However, increasing doses of FO affected the proportion of acetate, propionate, butyrate, and isobutyrate and A:P all quadratically. Compared with the control, only $\mathrm{CO}$ tended to increase the concentration of ammonia (Table 2).

\section{Abundances of Microorganisms}

The CO and FO had different effects on the abundances of all the rumen microorganisms analyzed ex- 
Table 1. Effect of coconut oil and fish oil on in vitro gas production, degradability, and $\mathrm{pH}^{1}$

\begin{tabular}{|c|c|c|c|c|c|c|c|c|c|c|}
\hline \multirow[b]{2}{*}{ Item } & \multirow[b]{2}{*}{ Control } & & & \multicolumn{2}{|c|}{$\mathrm{FO}$} & \multirow[b]{2}{*}{ SEM } & \multicolumn{4}{|c|}{ Effect ${ }^{2}$} \\
\hline & & $\mathrm{L}$ & $\mathrm{H}$ & $\mathrm{L}$ & $\mathrm{H}$ & & Oil & Oil $\times$ Dose & $\mathrm{CO}$ & $\mathrm{FO}$ \\
\hline Total gas (mmol) & 3.20 & 3.38 & 3.45 & 3.41 & 3.37 & 0.052 & 0.74 & 0.59 & $\mathrm{~L}$ & NS \\
\hline Methane (mmol) & 1.33 & 1.22 & 1.24 & 1.25 & 1.21 & 0.037 & 0.91 & 0.76 & $\mathrm{~L}^{*}$ & $\mathrm{~L}^{*}$ \\
\hline $\mathrm{CO}_{2}(\mathrm{mmol})$ & 1.79 & 1.96 & 2.01 & 1.98 & 2.01 & 0.049 & 0.81 & 0.98 & $\mathrm{~L}$ & $\mathrm{~L}$ \\
\hline NDF degradability (\%) & 54.1 & 49.1 & 40.7 & 48.5 & 46.1 & 1.59 & 0.30 & 0.22 & $\mathrm{~L}$ & $\mathrm{~L}$ \\
\hline $\mathrm{pH}$ & 6.35 & 6.23 & 6.20 & 6.21 & 6.21 & 0.010 & 0.78 & 0.40 & $\mathrm{Q}$ & $\mathrm{Q}$ \\
\hline
\end{tabular}

${ }^{1}$ Control = without any oil; $\mathrm{CO}=$ coconut oil; $\mathrm{FO}=$ fish oil; $\mathrm{L}$ and $\mathrm{H}$ represent 3.1 and $6.2 \mathrm{~mL} / \mathrm{L}$ of each oil, respectively.

${ }^{2} \mathrm{NS}=$ not significant $(P>0.10) ; \mathrm{L}=$ linear; $\mathrm{Q}=$ quadratic. When both $\mathrm{L}$ and $\mathrm{Q}$ effects were significant $(P<0.05)$, Q effect is presented in the table.

${ }^{*} \mathrm{~L}$ and $\mathrm{Q}$ effects showed a tendency $(P<0.10)$.

cept total bacteria and $R$. albus. Significant oil type $x$ dose interactions were also observed for the effect on abundance of protozoa and $F$. succinogenes (Table $3)$. The FO had relatively greater inhibitory effect on rumen methanogens than the CO. However, CO had higher suppressive effects on protozoa, $R$. flavefaciens, and $F$. succinogenes. Increasing doses of $\mathrm{CO}$ decreased the abundances of all the microorganisms analyzed quadratically except $R$. albus, whereas FO decreased total bacteria, protozoa, and F. succinogenes quadrati-

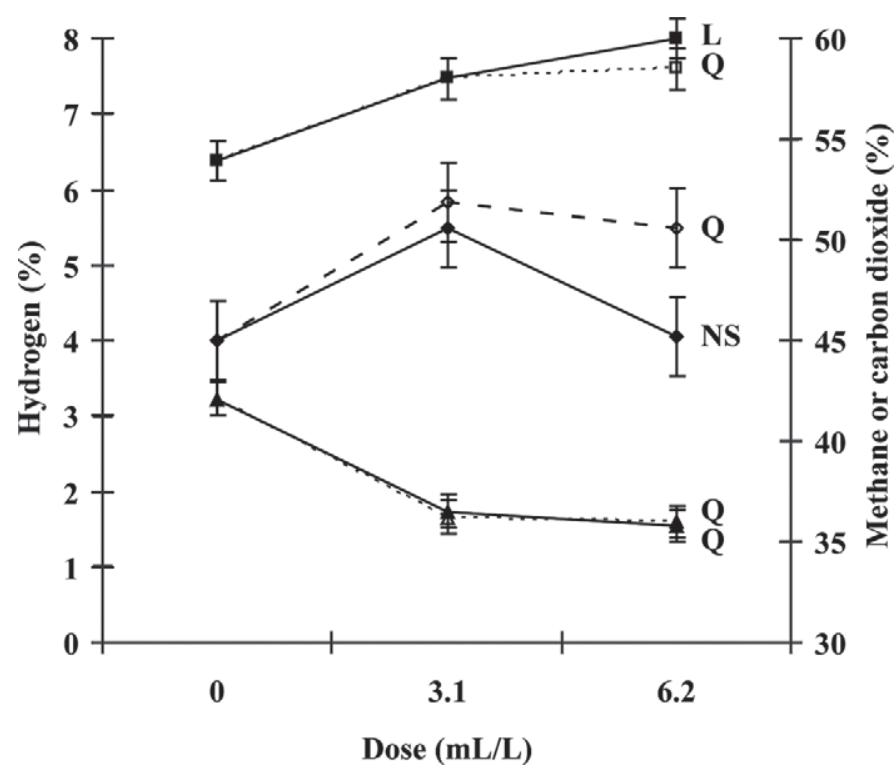

Figure 1. Effects of coconut oil (CO) and fish (FO) oil on concentrations of headspace gases: carbon dioxide $(\mathbf{\square}$; SEM $=1.00)$, hydrogen $(\bullet$ SEM $=0.52)$, and methane $(\boldsymbol{\Lambda} ; \mathrm{SEM}=0.81)$. Dotted and solid lines represent $\mathrm{CO}$ and $\mathrm{FO}$, respectively; $\mathrm{L}$ and $\mathrm{Q}$ represent significant $(P<0.01)$ linear and quadratic effect, respectively; NS, not significant $(P>0.10)$. cally and archaea linearly, with no effect on the $2 \mathrm{Ru}$ minococcus species.

\section{Diversity of Bacteria and Archaea}

The DGGE analysis clearly demonstrated that several archaeal populations diminished, evident from the weak bands in the CO cultures (Figure 2). The PCA plots for archaea also showed that the archaeal communities were clustered by oil type. Of the total variance, 42.1, 22.1, and $11.8 \%$ were explained by the first (PC 1 ), second (PC 2), and third (PC 3) principal components $(\mathbf{P C})$, respectively. As in the case of archaeal communities, the PCA plot indicated that bacterial communities were affected differently by $\mathrm{CO}$ and $\mathrm{FO}$ (Figure 3). The first $3 \mathrm{PC}$ explained $75 \%$ of the total variance in the bacterial communities. The MANOVA of the first $3 \mathrm{PC}$ showed that both the bacterial and archaeal communities differed between any pair of 5 treatments (low and high doses of $\mathrm{CO}$ and FO and the control), except between the high and the low doses of $\mathrm{CO}$ (CO-H and CO-L; Table 4).

Bacterial diversity indices were not affected by oil type, oil type $\times$ dose interaction, or different doses of FO, but increasing doses of CO increased Shannon diversity $(H)$ and evenness indices, and decreased dominance index quadratically (Table 5). In contrast to the above indices for bacteria, the indices for archaea were affected by oil type and oil type $\times$ dose interactions. Evenness and $H$ index were lower for $\mathrm{CO}$ than for $\mathrm{FO}$, and dominance index was greater for $\mathrm{CO}$ than for FO. Increasing doses of $\mathrm{CO}$ decreased evenness and $H$ indices quadratically and increased dominance index linearly. The FO had no effect on $H$ index, but increased the evenness index linearly and tended to decrease dominance index linearly. The PL curves revealed that the evenness of the archaeal community markedly decreased 
Table 2. Effect of coconut oil and fish oil on concentrations of total VFA and ammonia, and molar percentages of individual fatty acids in vitro ${ }^{1}$

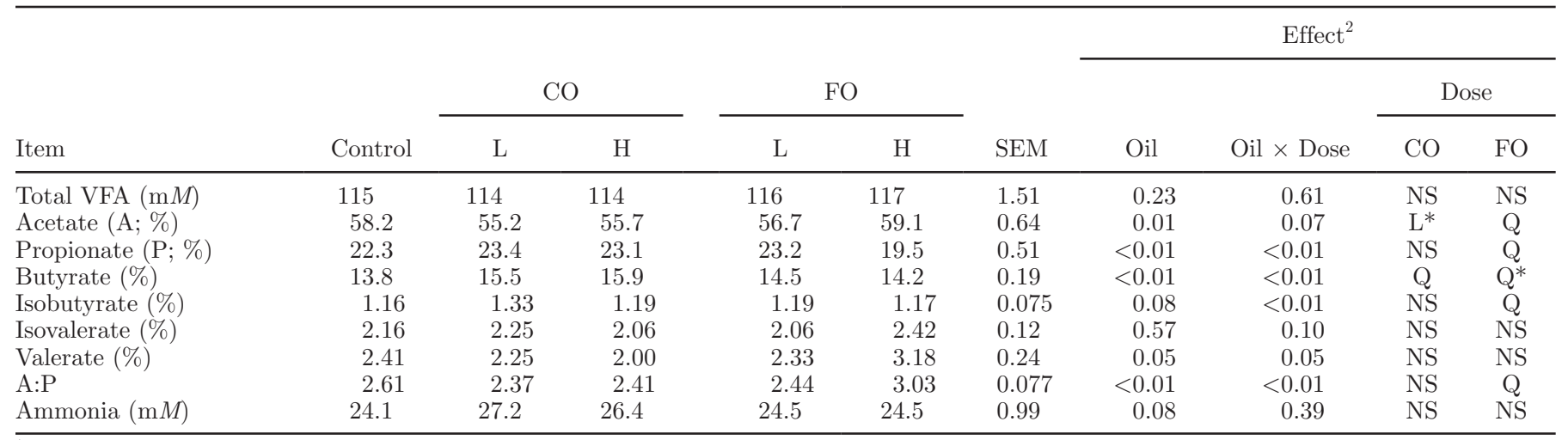

${ }^{1}$ Control = without any oil; $\mathrm{CO}=$ coconut oil; $\mathrm{FO}=$ fish oil; $\mathrm{L}$ and $\mathrm{H}$ represent 3.1 and $6.2 \mathrm{~mL} / \mathrm{L}$ of each oil, respectively.

${ }^{2} \mathrm{NS}=$ not significant $(P>0.10) ; \mathrm{L}=$ linear; $\mathrm{Q}=$ quadratic. When both $\mathrm{L}$ and $\mathrm{Q}$ effects were significant $(P<0.05), \mathrm{Q}$ effect is presented in the table.

$* \mathrm{~L}$ and $\mathrm{Q}$ effects showed a tendency $(P<0.10)$.

due to the addition of $\mathrm{CO}$, but not FO. The evenness of the bacterial communities was not affected notably by either $\mathrm{CO}$ or FO (Figure 4). It was observed that $25 \%$ of all the bands for the archaeal communities accounted for $61 \%$ (lowest evenness) and $47 \%$ (highest evenness) of the cumulative species abundances for the low dose of $\mathrm{CO}$ and the high dose of FO, respectively (Figure 4). For the bacterial communities, the highest and lowest evenness of species distribution (i.e., $25 \%$ of the bands in the cultures corresponding with 58 and $63 \%$ of the cumulative species abundances) were observed for $\mathrm{CO}$ at the high and the low doses, respectively.

\section{DISCUSSION}

\section{Total Gas, Methane, Carbon Dioxide, and Hydrogen Production}

Both $\mathrm{CO}$ and FO decreased methane production at both doses tested, which agrees with previous studies
(Dohme et al., 1999; Fievez et al., 2003; Jordan et al., 2006). However, FO or CO supplementation at 3.1 $\mathrm{mL} / \mathrm{L}$ resulted in only about a $9 \%$ decrease in methane production and no further decrease was evident at the $6.2 \mathrm{~mL} / \mathrm{L}$ dose. In an in vitro study, $\mathrm{FO}$ at $3 \mathrm{~mL} / \mathrm{L}$ did not inhibit methane production after $24 \mathrm{~h}$ of incubation, but reduced methane yield by $80 \%$ after $48 \mathrm{~h}$ of incubation (Fievez et al., 2003). Free fatty acids, or mono acylglycerol, are directly inhibitory to microorganisms, whereas fats are not (Demeyer and Henderickx, 1967; Desbois and Smith, 2010). It is thus hypothesized that the short incubation $(24 \mathrm{~h})$ might not have allowed for adequate lipolysis in the in vitro cultures. A comparative study using both oils and their major free fatty acids will help to test this premise.

Fish oil and coconut oil differ considerably in fatty acid composition. Fish oil contains mainly long-chain fatty acids, including UFA (\% of total fatty acids), such as C16:0 (13.5-17.0), C18:1 (12.5-15.0), C20:5n-3 (5.8-18.7), C22:1 (2.2-23.0), and C22:6n-3 (7.6-11.7;

Table 3. Effect of coconut oil and fish oil on abundances ( $\log _{10}$ copies of rrs genes) of total bacteria, archaea, protozoa, and major fibrolytic bacteria in the ruminal cultures ${ }^{1}$

\begin{tabular}{|c|c|c|c|c|c|c|c|c|c|c|}
\hline Item & Control & & & \multicolumn{2}{|c|}{$\mathrm{FO}$} & SEM & \multicolumn{4}{|c|}{ Effect $^{2}$} \\
\hline Total bacteria & 11.7 & 10.9 & 10.8 & 11.0 & 11.1 & 0.11 & 0.19 & 0.32 & $\mathrm{Q}$ & $\mathrm{Q}$ \\
\hline Archaea & 7.92 & 7.79 & 7.60 & 7.64 & 7.49 & 0.041 & 0.03 & 0.23 & $\mathrm{Q}$ & $\mathrm{L}$ \\
\hline Protozoa & 9.23 & 7.65 & 7.65 & 8.90 & 8.94 & 0.058 & $<0.01$ & $<0.01$ & $\mathrm{Q}$ & $\mathrm{Q}$ \\
\hline Fibrobacter succinogenes & 7.16 & 5.21 & 5.01 & 6.50 & 6.63 & 0.072 & $<0.01$ & $<0.01$ & $\mathrm{Q}$ & $\mathrm{Q}$ \\
\hline
\end{tabular}

${ }^{1}$ Control $=$ without any oil; $\mathrm{CO}=$ coconut oil; $\mathrm{FO}=$ fish oil; $\mathrm{L}$ and $\mathrm{H}$ represent 3.1 and $6.2 \mathrm{~mL} / \mathrm{L}$ of each oil, respectively.

${ }^{2} \mathrm{NS}=$ not significant $(P>0.10) ; \mathrm{L}=$ linear; $\mathrm{Q}=$ quadratic. When both $\mathrm{L}$ and $\mathrm{Q}$ effects were significant $(P<0.05), \mathrm{Q}$ effect is presented in the table. 

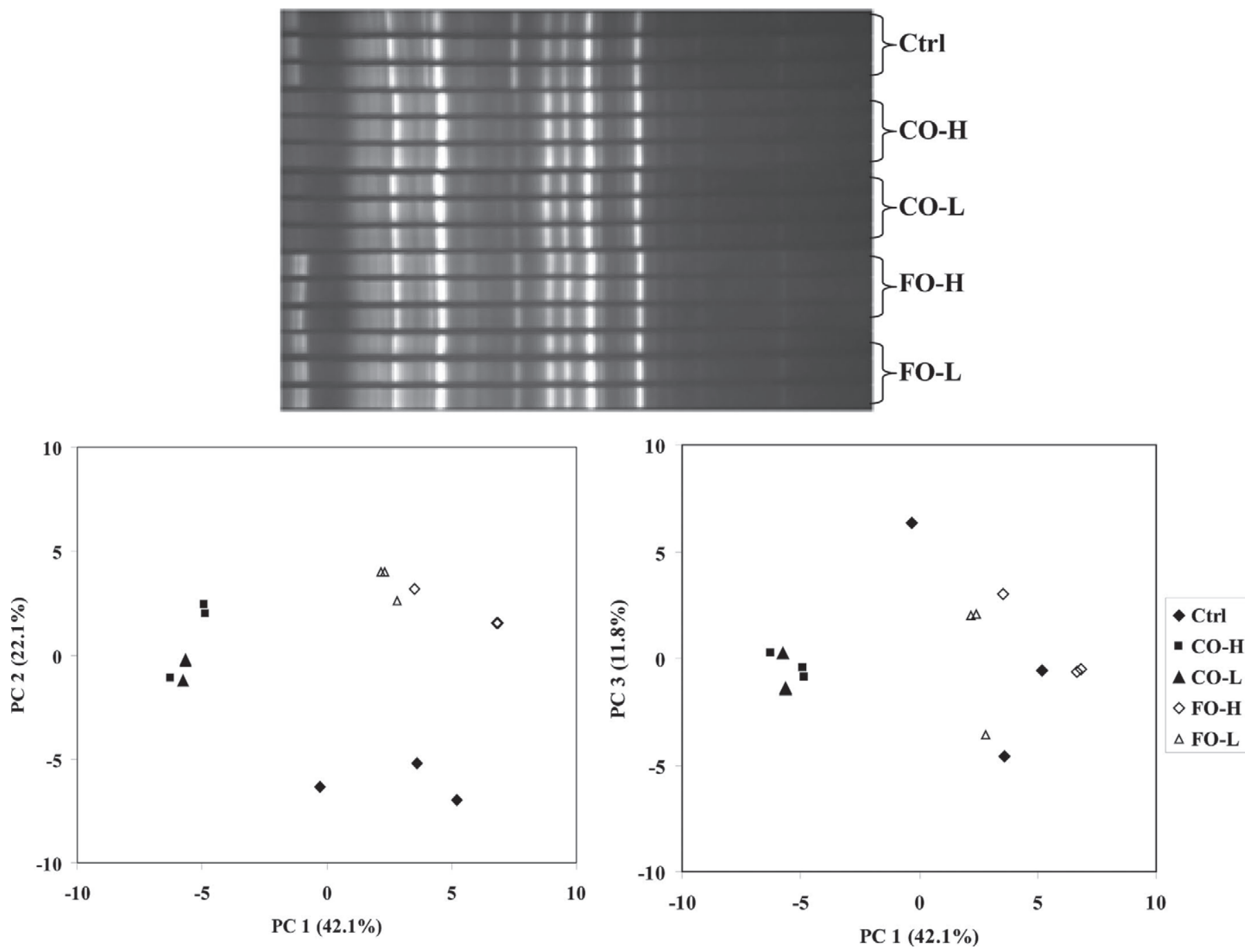

Figure 2. Denaturing gradient gel electrophoresis (DGGE) profile of archaea (upper panel) and principal component (PC) analysis plots of the DGGE profiles (lower panels). Ctrl = control (without any oil); CO-H and CO-L = coconut oil at high and low doses, respectively; FO-H and $\mathrm{FO}-\mathrm{L}=$ fish oil at high and low doses, respectively. All the treatments were evaluated in triplicate.

Fievez et al., 2003). In contrast, $\mathrm{CO}$ is rich in MCFA, such as C12:0 $(\sim 42.2)$ and C14:0 ( 17.7; Liu et al., 2011). Fatty acids C12:0 and C18:3 have been shown to be highly inhibitory to methanogenesis compared with other dietary fatty acids (A. K. Patra, unpublished data). In addition, methane emissions appear to be more associated with concentrations of MUFA and PUFA compared with total concentrations of SFA in diets (A. K. Patra, unpublished data). Therefore, C12 and $\mathrm{C} 14$ fatty acids in $\mathrm{CO}$ and long-chain UFA in FO could be primarily accountable for the lower methanogenesis seen in the in vitro cultures.

A decrease in NDF digestion could result in diminished availability of hydrogen for methanogenesis (Dohme et al., 1999); a decrease in protozoa numbers could lower protozoa-associated methanogenesis
(Lovett et al., 2003; Machmuller et al., 2003); and direct inhibition of methanogenic activity (Machmuller, 2006) has been proposed as an explanation for reduction in methane production by dietary fats. In this study, although fiber digestibility decreased, hydrogen concentrations did not decrease in the FO cultures and even increased in the $\mathrm{CO}$ cultures. Additionally, the protozoal population was reduced to a greater degree by $\mathrm{CO}$ than by $\mathrm{FO}$, yet both $\mathrm{CO}$ and $\mathrm{FO}$ decreased methane outputs and concentrations to similar levels. Thus, direct toxicity of $\mathrm{CO}$ and FO on methanogens, rather than reduced hydrogen availability or protozoaassociated methanogen, was probably the major mode of methanogenesis inhibition seen in the present study. Indeed, the abundances of methanogens were lowered by $\mathrm{CO}$ and FO (Table 3). Despite similar reduction in 
Table 4. Pairwise comparisons of denaturing gradient gel electrophoresis profiles of bacteria and archaea as affected by coconut oil and fish oil ${ }^{1,2}$

\begin{tabular}{|c|c|c|c|c|c|c|c|c|}
\hline Item & \multicolumn{4}{|c|}{ Total bacteria } & \multicolumn{4}{|c|}{ Archaea } \\
\hline $\mathrm{CO}-\mathrm{H}$ & $<0.01$ & & & & 0.06 & & & \\
\hline FO-H & $<0.01$ & 0.04 & 0.01 & & $<0.01$ & $<0.01$ & $<0.01$ & \\
\hline FO-L & $<0.01$ & $<0.01$ & $<0.01$ & 0.05 & 0.03 & $<0.01$ & $<0.01$ & $<0.01$ \\
\hline
\end{tabular}

${ }^{1} \mathrm{CO}-\mathrm{H}$ and $\mathrm{CO}-\mathrm{L}=$ coconut oil at high and low doses, respectively; FO-H and FO-L $=$ fish oil at high and low doses, respectively.

${ }^{2} P$-values were calculated from the first 3 principal components using multivariate ANOVA.

methane production by both oils, the hydrogen concentrations were lower in the $\mathrm{FO}$ than in the $\mathrm{CO}$ cultures. This discrepancy may be attributed to the consumption of hydrogen during biohydrogenation of UFA present in FO. It is difficult to determine, however, how much biohydrogenation and direct toxicity of UFA contributes, respectively, to the observed reduction in methane production by FO.
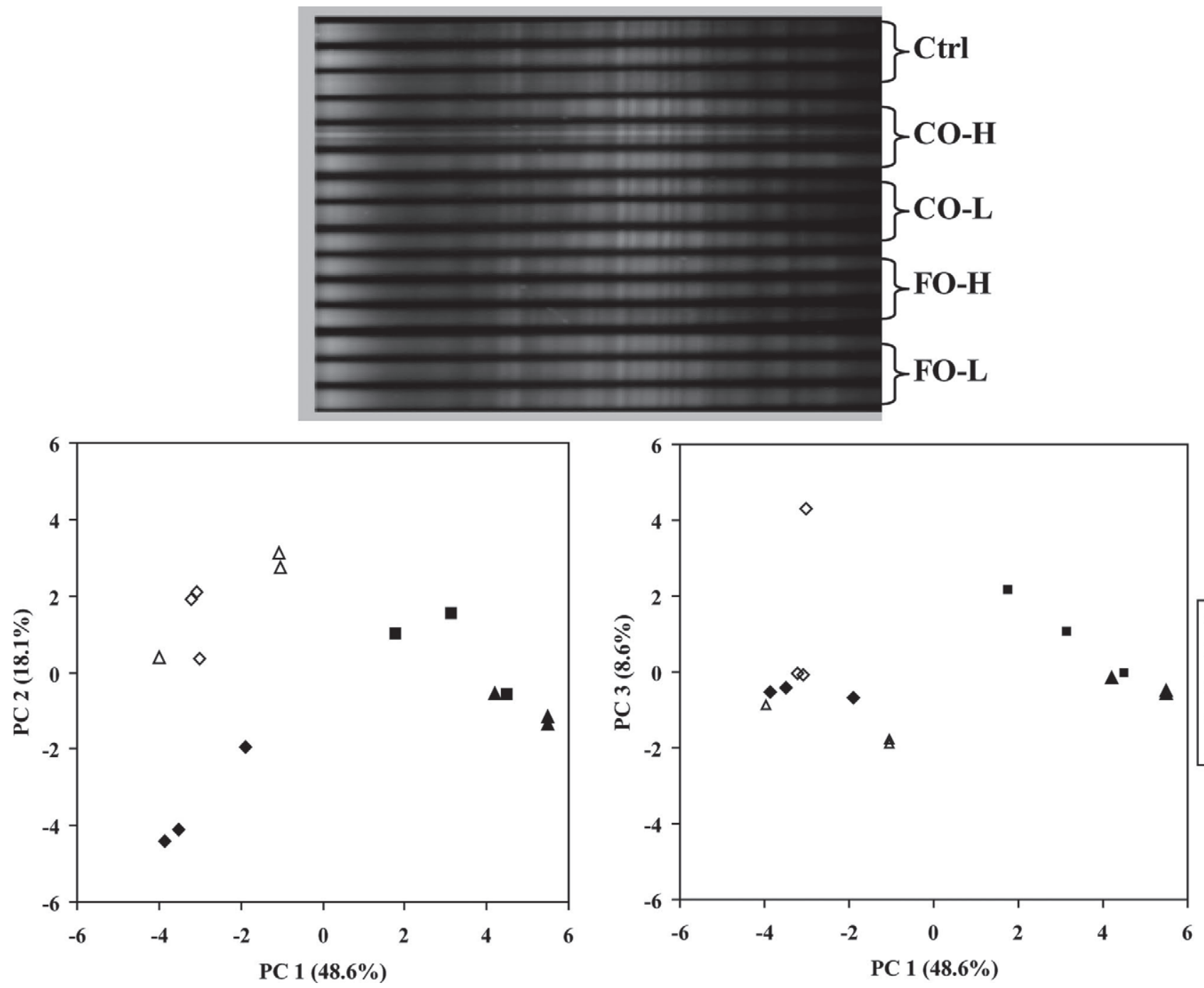

Figure 3. Denaturing gradient gel electrophoresis (DGGE) profile of bacteria (upper panel) and principal component (PC) analysis plots of the DGGE profiles (lower panels). Ctrl, control (without any oil); CO-H and CO-L, coconut oil at high and low doses, respectively; FO-H and FO-L, fish oil at high and low doses, respectively. All the treatments were evaluated in triplicate. 
Table 5. Effect of coconut oil and fish oil on diversity indices of rumen bacteria and archaea ${ }^{1}$

\begin{tabular}{|c|c|c|c|c|c|c|c|c|c|c|}
\hline \multirow[b]{2}{*}{ Item } & \multirow[b]{2}{*}{ Control } & & & \multicolumn{2}{|c|}{ FO } & \multirow[b]{2}{*}{ SEM } & \multicolumn{4}{|c|}{ Effect $^{2}$} \\
\hline & & $\mathrm{L}$ & $\mathrm{H}$ & $\mathrm{L}$ & $\mathrm{H}$ & & Oil & Oil $\times$ Dose & $\mathrm{CO}$ & $\mathrm{FO}$ \\
\hline \multicolumn{11}{|l|}{ Bacteria } \\
\hline$H$ index & 2.66 & 2.83 & 2.73 & 2.72 & 2.72 & 0.031 & 0.15 & 0.15 & $\mathrm{Q}$ & NS \\
\hline Evenness & 0.869 & 0.902 & 0.886 & 0.887 & 0.890 & 0.010 & 0.68 & 0.64 & $\mathrm{Q}$ & NS \\
\hline$H$ index & 2.90 & 2.71 & 2.70 & 2.95 & 2.95 & 0.021 & $<0.01$ & $<0.01$ & $\mathrm{Q}$ & NS \\
\hline Evenness & 0.934 & 0.944 & 0.916 & 0.941 & 0.946 & 0.003 & $<0.01$ & 0.01 & $\mathrm{Q}$ & $\mathrm{L}$ \\
\hline Dominance & 0.063 & 0.075 & 0.078 & 0.059 & 0.059 & 0.002 & $<0.01$ & 0.02 & $\mathrm{~L}$ & $\mathrm{~L}^{*}$ \\
\hline
\end{tabular}

${ }^{1}$ Control = without any oil; $\mathrm{CO}=$ coconut oil; $\mathrm{FO}=$ fish oil; $\mathrm{L}$ and $\mathrm{H}$ represent 3.1 and $6.2 \mathrm{~mL} / \mathrm{L}$ of each oil, respectively.

${ }^{2} \mathrm{NS}=$ not significant $(P>0.10) ; \mathrm{L}=$ linear; $\mathrm{Q}=$ quadratic. When both $\mathrm{L}$ and $\mathrm{Q}$ effects were significant $(P<0.05)$, $\mathrm{Q}$ effect is presented in the table.

*L effect showed a tendency $(P<0.10)$.

\section{Digestibility and VFA}

Decreases in digestibility have been recorded after addition of oils to diets (Dong et al., 1997; Dohme et al., 1999). The marked decrease in feed digestibility was not accompanied by any decrease in abundances of $R$. albus for both oils, or $R$. flavefaciens for $\mathrm{FO}$ - although the abundance of $F$. succinogenes was reduced by both oils. Rumen ciliates, which have been shown to contribute up to $30 \%$ of total microbial fiber digestion (Demeyer, 1981), were substantially suppressed by both oils. Decreased F. succinogenes and protozoa might, therefore, be mainly responsible for the depression in fiber digestion observed in this study. It should be noted that the high dose of oils did not elicit greater inhibitory effects on these populations compared with the low dose of oils, although fiber digestion was considerably lower for the high dose than for the low dose of both oils. Thus, hindrance in attachment of fibrolytic bacteria to the feed substrates by the oils adsorbed onto the feed particles should not be ruled out as another reason contributable to the depressed digestibility. This explanation has been contested in a study using soy oil hydrolysate (Broudiscou et al., 1990). A further study
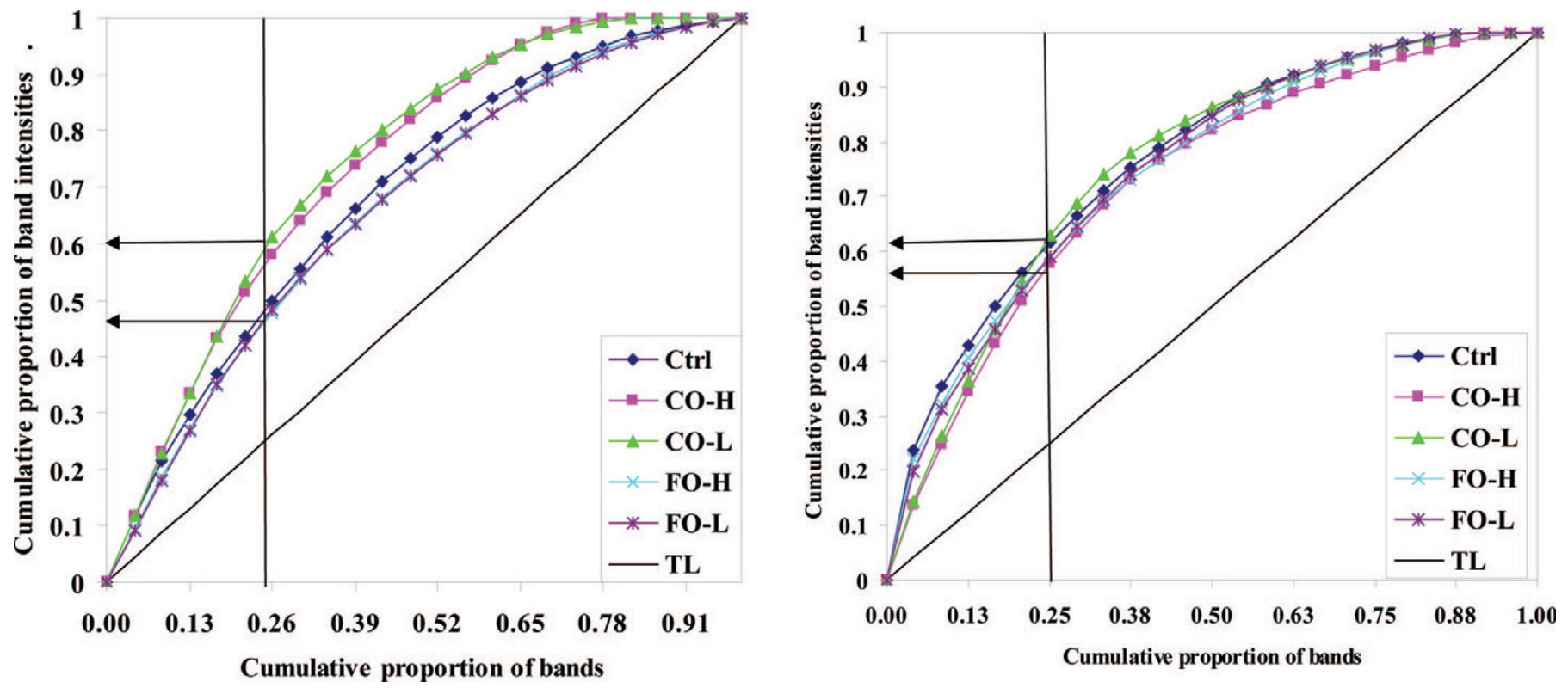

Figure 4. Pareto-Lorenz distribution curves based on denaturing gradient gel electrophoresis (DGGE) profiles of the archaeal (left) and bacterial (right) communities in rumen cultures supplemented with coconut or fish oils. Arrows indicate the range of cumulative band intensities corresponding to $25 \%$ of all the bands combined. Ctrl = control (without any oil); CO-H and CO-L = coconut oil at high and low doses, respectively; FO-H and FO-L = fish oil at high and low doses, respectively; TL = theoretical evenness line. Color version available in the online PDF. 
that directly analyzes attachment of fibrolytic bacteria to fibrous feed particles and the cellulase activities associated with the feed particles in the absence and presence of lipid will help determine if, and to what extent, physical coating of feed particles by dietary lipids hinders feed digestibility.

Addition of $\mathrm{CO}$ or FO did not alter the concentrations of total VFA despite a marked reduction of digestibility of the feed substrate. This is consistent with the study of Dohme et al. (1999). Fats and oils contain glycerol (8-14\% of total fats), which, after being released from oils, can be metabolized to VFA. Glycerol fermentation to VFA might have compensated for the reduced VFA fermentation from the feed substrate. Glycerol fermentation might also have contributed to the small increase in production of total gas, $\mathrm{CO}_{2}$, and $\mathrm{H}_{2}$. In agreement with this study, similar findings in VFA concentrations (Liu et al., 2011), proportion of acetate (Kim et al., 2008; Liu et al., 2011), propionate (Machmuller et al., 2000; Kongmun et al., 2010), and A:P ratio (Kongmun et al., 2010) were noted in other studies of the same nature.

\section{Abundance of Microbial Population}

Several studies have reported that oils, especially those containing MCFA and long-chain UFA, were toxic to rumen microorganisms. Henderson (1973) showed in vitro that MCFA inhibited strains of Butyrivibrio spp. and Ruminococcus spp. However, cellulolytic bacterial populations in rumen fluid were only significantly reduced when $10 \% \mathrm{CO}$ was added to a hay-based ration but not to a concentrate-based ration (Dong et al., 1997). Nonetheless, this study demonstrated that CO is more toxic to protozoa and fibrolytic bacteria than FO. The higher toxicity of CO to bacteria and protozoa observed in the present study might be attributed to higher solubility of MCFA (C8 to C14) present in $\mathrm{CO}$ than long-chain fatty acids $(>\mathrm{C} 14)$ found in $\mathrm{FO}$ in the cultures, and thus more interaction with cells (Buffo and Holley, 2006).

Free fatty acids, with their surfactant properties, can disrupt membrane integrity, impair nutrient uptake, and inhibit membrane enzyme activity and energy production, leading to cell death (Desbois and Smith, 2010). Oils, especially CO, were more inhibitory to the growth of F. succinogenes (a gram-negative bacterium) than to growth of Ruminococcus spp. (gram-positive). Indeed, Kongmun et al. (2010) reported that CO decreased the abundance of $F$. succinogenes but not that of $R$. albus or $R$. flavefaciens in vitro. Such differential inhibitions were also noted in steers fed $4 \% \mathrm{FO}$ and sunflower oil (Liu et al., 2012) and in sheep receiving CO-supplemented diets (Liu et al., 2011). However, not all studies agreed with these findings. Yang et al. (2009), for example, reported that the abundance of $B$. fibrisolvens (gram-positive), R. albus (gram-positive), and $F$. succinogenes decreased by 18,42 , and $67 \%$, respectively, whereas that of $R$. flavefaciens (grampositive) was unchanged when cows were fed supplemental soybean or linseed oil ( $4 \%$ of DM). The reason for greater antibacterial action of $\mathrm{CO}$ and $\mathrm{FO}$ against gram-negative bacteria is not clear, but oils might more readily adsorb onto the lipophilic outer membrane of gram-negative bacteria, causing greater disruption of the membranes. However, gram-positive bacteria have been reported to be more susceptible to free fatty acids than gram-negative bacteria (Desbois and Smith, 2010). In addition to the cell outer membrane and cell wall, other cell envelope structures, such as the glycocalyx, may affect the susceptibility of a microbe to free fatty acids. The dietary environment might also affect the toxicity of a free fatty acid to different groups of microbes.

\section{Communities of Bacteria and Archaea}

The effects of dietary oil supplementation on rumen bacterial and archaeal communities appeared to depend on the type and dose of the oils, corroborating a previous report in which the effect of FO was concentrationdependent (Kim et al., 2008). The intensity of several DGGE bands was reduced by CO, consistent with the decrease of archaea by CO. Similarly, the abundance of archaea was decreased by $\mathrm{FO}$ as determined by qPCR, but was not reflected by decreased intensity of the DGGE bands. Thus, CO might have selectively inhibited certain ruminal archaeal populations. This contradicts Hristov et al. (2009), who reported that $\mathrm{CO}$ did not selectively inhibit ruminal methanogen populations, as evidenced from DGGE profiles, despite a substantial decrease in methane output by $\mathrm{CO}$ in dairy cows fed $530 \mathrm{~g}$ of $\mathrm{CO} /$ day. The DGGE profiles obtained from ruminal digesta showed major changes in the bacterial community in steers fed $3 \%$ FO, but not 1\% FO (Kim et al., 2008). Changes in the structure of the bacterial community, specifically with Butyrivibrio spp., were observed in cows receiving DHA-containing microalgae (Boeckaert et al., 2008). The increased $H$ index of bacteria by the oils, especially $\mathrm{CO}$ at a low dose, might be associated with the increased bacterial populations involved in fat metabolism. Certain bacterial groups, such as potentially uncultured Lachnospiraceae strains or Quinella-related bacteria, detected by terminal RFLP analysis, exhibited variations in their relative frequency in sheep fed microalgae and sunflower oil (Belenguer et al., 2010; Toral et al., 2012). The PL curves are useful to describe the functional- 
ity of the microbial communities in complex microbial ecosystems (Wittebolle et al., 2009). In this study, the PL species distribution curve for bacteria signified that only minor differences in the functionality of bacterial community had occurred, whereas the functionality of archaeal community, especially in the $\mathrm{CO}$ supplemented cultures, was greatly affected by oil supplementation.

\section{CONCLUSIONS}

In summary, both $\mathrm{CO}$ and FO decreased methane quadratically and digestibility linearly with increasing doses with similar magnitudes (i.e., no effect of oil type). However, these oils influenced the abundance of select microbial populations and functional organization of the bacterial and archaeal communities to different magnitudes. Coconut oil exerted greater inhibitory effects on cellulolytic bacteria ( $F$. succinogenes and $R$. flavefaciens) and protozoa than did FO. Coconut oil distinctly modified archaeal community organization and diversity, whereas FO had little effect. Changes in the methane production were associated with changes in the structure of the archaeal community for $\mathrm{CO}$, but not for FO. Thus, this study demonstrated that MCFA and long-chain UFA shift rumen bacterial and archaeal communities distinctly and to different extents. Further studies on combinations of oils containing MCFA and long-chain UFA should be focused, which might decrease methane emissions additively while improving the quality of meat and milk of ruminant sources.

\section{ACKNOWLEDGMENTS}

This work was supported in part by an OARDC grant (2010-007). A. K. Patra's tenure at The Ohio State University was supported by a BOYSCAST fellowship from the Department of Science and Technology, India.

\section{REFERENCES}

Beauchemin, K. A., M. Kreuzer, F. O'Mara, and T. A. McAllister. 2008. Nutritional management for enteric methane abatement: A review. Aust. J. Exp. Agric. 48:21-27.

Belenguer, A., P. G. Toral, P. Frutos, and G. Hervás. 2010. Changes in the rumen bacterial community in response to sunflower oil and fish oil supplements in the diet of dairy sheep. J. Dairy Sci. 93:3275-3286.

Boeckaert, C., B. Vlaeminck, V. Fievez, L. Maignien, J. Dijkstra, and N. Boon. 2008. Accumulation of trans C-18:1 fatty acids in the rumen after dietary algal supplementation is associated with changes in the Butyrivibrio community. Appl. Environ. Microbiol. 74:6923-6930.

Broudiscou, L., C. J. Van Nevel, and D. I. Demeyer. 1990. Effect of soya oil hydrolysate on rumen digestion in defaunated and refaunated sheep. Anim. Feed Sci. Technol. 30:51-67.

Buffo, R. A., and R. A. Holley. 2006. Effects of food processing on disease agents. Page 713 in Foodborne Infections and Intoxications,
H. P. Reimann, and D. O. Cliver, ed. Elsevier, Academic Press, San Diego, CA.

Coppock, C. E., and D. L. Wilks. 1991. Supplemental fat in highenergy rations for lactating cows: Effects on intake, digestion, milk yield, and composition. J. Anim. Sci. 69:3826-3837.

Cosgrove, G. P., G. C. Waghorn, C. B. Anderson, J. S. Peter, A Smith, G. Molano, and M. Deighton. 2008. The effect of oils fed to sheep on methane production and digestion of ryegrass pasture. Aust. J. Exp. Agric. 48:189-192.

Demeyer, D. I. 1981. Rumen microbes and digestion of plant cell walls. Agric. Environ. 6:295-337.

Demeyer, D. I., and H. K. Henderickx. 1967. The effect of C18 unsaturated fatty acids on methane production in vitro by mixed rumen bacteria. Biochim. Biophys. Acta 137:484-497.

Desbois, A. P., and V. J. Smith. 2010. Antibacterial free fatty acids: Activities, mechanisms of action and biotechnological potential. Appl. Microbiol. Biotechnol. 85:1629-1642.

Dohme, F. A. Machmüller, A. Wasserfallen, and M. Kreuzer. 1999. The role of the rumen ciliate protozoa for methane suppression caused by coconut oil. Lett. Appl. Microbiol. 29:187-192.

Dong, Y., H. D. Bae, T. A. McAllister, G. W. Mathison, and K. J. Cheng. 1997. Lipid induced depression of methane production and digestibility in the artificial rumen system (RUSITEC). Can. J. Anim. Sci. 77:269-278.

Fievez, V., F. Dohme, M. Danneels, K. Raes, and D. I. Demeyer. 2003. Fish oils as potent rumen methane inhibitors and associated effects on rumen fermentation in vitro and in vivo. Anim. Feed Sci. Technol. 104:41-58.

Henderson, C. 1973. The effects of fatty acids on pure cultures of rumen bacteria. J. Agric. Sci. 81:107-112.

Hristov, A. N., M. Vander Pol, M. Agle, S. Zaman, C. Schneider, P. Ndegwa, V. K. Vaddella, K. Johnson, K. J. Shingfield, and S. K. Karnati. 2009. Effect of lauric acid and coconut oil on ruminal fermentation, digestion, ammonia losses from manure, and milk fatty acid composition in lactating cows. J. Dairy Sci. 92:5561-5582.

Johnson, K. A., and D. A. Johnson. 1995. Methane emissions from cattle. J. Anim. Sci. 73:2483-2492.

Jordan, E., D. K. Lovett, F. J. Monahan, J. Callan, B. Flynn, and F. P. O'Mara. 2006. Effect of refined coconut oil or copra meal on methane output and on intake and performance of beef heifers. J. Anim. Sci. 84:162-170.

Kim, E. J., S. A. Huws, M. R. F. Lee, J. D. Wood, S. M. Muetzel, R. J. Wallace, and N. D. Scollan. 2008. Fish oil increases the duodenal flow of long chain polyunsaturated fatty acids and trans-11 18:1 and decreases 18:0 in steers via changes in the rumen bacteria community. J. Nutr. 138:889-896.

Kongmun, P., M. Wanapat, P. Pakdee, and C. Navanukraw. 2010. Effect of coconut oil and garlic powder on in vitro fermentation using gas production technique. Livest. Sci. 127:38-44.

Liu, H., V. Vaddella, and D. Zhou. 2011. Effects of chestnut tannins and coconut oil on growth performance, methane emission, ruminal fermentation, and microbial populations in sheep. J. Dairy Sci. 94:6069-6077

Liu, S. J., D. P. Bu, J. Q. Wang, L. Liu, S. Liang, H. Y. Wei, L. Y. Zhou, D. Li, and J. J. Loor. 2012. Effect of incremental levels of fish oil supplementation on specific bacterial populations in bovine ruminal fluid. J. Anim. Physiol. Anim. Nutr. (Berl.) 96:9-16.

Lock, A. L., and D. E. Bauman. 2004. Modifying milk fat composition of dairy cows to enhance fatty acids beneficial to human health. Lipids 39:1197-1206.

Lourenço, M., E. Ramos-Morales, and R. J. Wallace. 2010. The role of microbes in rumen lipolysis and biohydrogenation and their manipulation. Animal 4:1008-1023.

Lovett, D., S. Lovell, L. Stack, J. Callan, M. Finlay, J. Conolly, and F. P. O'Mara. 2003. Effect of forage/concentrate ratio and dietary coconut oil level on methane output and performance of finishing beef heifers. Livest. Prod. Sci. 84:135-146.

Machmuller, A. 2006. Medium-chain fatty acids and their potential to reduce methanogenesis in domestic ruminants. Agric. Ecosyst. Environ. 112:107-114. 
Machmuller, A., D. A. Ossowski, and M. Kreuzer. 2000. Comparative evaluation of the effects of coconut oil, oilseeds and crystalline fat on methane release, digestion and energy balance in lambs. Anim. Feed Sci. Technol. 85:41-60.

Machmuller, A., C. R. Soliva, and M. Kreuzer. 2003. Effect of coconut oil and defaunation treatment on methanogenesis in sheep. Reprod. Nutr. Dev. 43:41-55.

Martin, C., D. P. Morgavi, and D. Moreau. 2010. Methane mitigation in ruminants: From microbe to the farm scale. Animal 4:351-365.

McAllister, T. A., E. K. Okine, G. W. Mathison, and K. J. Cheng. 1996. Dietary environmental and microbiological aspects of methane production in ruminants. Can. J. Anim. Sci. 76:231-243.

Menke, K. H., and H. Steingass. 1988. Estimation of the energetic feed value from chemical analysis and in vitro gas production using rumen fluid. Anim. Res. Dev. 28:7-55.

Mertens, B., N. Boon, and W. Verstraete. 2005. Stereospecific effect of hexachlorocyclohexane on activity and structure of soil methanotrophic communities. Environ. Microbiol. 7:660-669.

Patra, A. K. 2012. Enteric methane mitigation technologies for ruminant livestock: A synthesis of current research and future directions. Environ. Monit. Assess. 184:1929-1952.

Patra, A. K., and J. Saxena. 2010. A new perspective on the use of plant secondary metabolites to inhibit methanogenesis in ruminants. Phytochemistry 71:1198-1222.

Patra, A. K., J. Stiverson, and Z. Yu. 2012. Effects of quillaja and yucca saponins on communities and select populations of rumen bacteria and archaea, and fermentation in vitro. J. Appl. Microbiol. 113:1329-1340.

Patra, A. K., and Z. Yu. 2012. Effects of essential oils on methane production, fermentation, abundance and diversity of rumen microbial populations. Appl. Environ. Microbiol. 78:4271-4280.

SAS Institute. 2001. Statistical Analysis Systems Institute. Version 8 SAS Institute Inc., Cary, NC.
Stiverson, J., M. Morrison, and Z. Yu. 2011. Populations of select cultured and uncultured bacteria in the rumen of sheep and the effect from diets and ruminal fractions. Int. J. Microbiol. 2011:750613.

Sylvester, J. T., S. K. Karnati, Z. Yu, M. Morrison, and J. L. Firkins. 2004. Development of an assay to quantify rumen ciliate protozoal biomass in cows using real-time PCR. J. Nutr. 134:3378-3384.

Toral, P. G., A. Belenguer, K. J. Shingfield, G. Hervas, V. Toivonen and P. Frutos. 2012. Fatty acid composition and bacterial community changes in the rumen fluid of lactating sheep fed sunflower oil plus incremental levels of marine algae. J. Dairy Sci. 95:794-806.

Wittebolle, L., M. Marzorati, L. Clement, A. Balloi, D. Daffonchio, K. Heylen, P. De Vos, W. Verstraete, and N. Boon. 2009. Initial community evenness favours functionality under selective stress. Nature 458:623-626.

Yang, S. L., D. P. Bu, J. Q. Wang, Z. Y. Hu, D. Li, H. Y. Wei, L. Y. Zhou, and J. J. Loor. 2009. Soybean oil and linseed oil supplementation affect profiles of ruminal microorganisms in dairy cows. Animal 3:1562-1569.

Yu, Z., R. Garcia-Gonzalez, F. L. Schanbacher, and M. Morrison. 2008. Evaluations of different hypervariable regions of archaeal 16S rRNA genes in profiling of methanogens by archaea-specific PCR and denaturing gradient gel electrophoresis. Appl. Environ. Microbiol. 74:889-893.

Yu, Z., F. C. Michel Jr., G. Hansen, T. Wittum, and M. Morrison. 2005. Development and application of real-time PCR assays for quantification of genes encoding tetracycline resistance. Appl. Environ. Microbiol. 71:6926-6933.

Yu, Z., and M. Morrison. 2004a. Improved extraction of PCR-quality community DNA from digesta and fecal samples. Biotechniques $36: 808-812$.

Yu, Z., and M. Morrison. 2004b. Comparisons of different hypervariable regions of rrs genes for use in fingerprinting of microbial communities by PCR-denaturing gradient gel electrophoresis. Appl. Environ. Microbiol. 70:4800-4806. 